\title{
Pengembangan Lembar Kerja Sis wa (LKS) IPA Terpadu Menggunakan Kooperatif Tipe STAD
}

\author{
Titik Rahayu ${ }^{1}$, Syafrimen ${ }^{2}$, Widya Wati ${ }^{3}$, Yuberti ${ }^{4}$ \\ ${ }^{1,2,3,4}$ Fakultas Tarbiyah dan Keguruan, Universitas Islam Negeri (UIN) Raden Intan Lampung \\ ${ }^{1}$ titikrahayu@ radenintan.ac.id, 2 syafrimen@ radenintan.ac.id, \\ ${ }^{3}$ widyawati@ radenintan.ac.id, ${ }^{4}$ yuberti@ radenintan.ac.id
}

\begin{abstract}
Abstrak
Penggunaan bahan ajar Terpadu dalam pengajaran dan pembelajaran IPA sangat penting, untuk mendukung siswa memperoleh pengetahuan dan keterampilan yang komprehensif, serta menjadikan proses pembelajaran lebih berkesan. Guru harus pandai memilih metode dan mengemas bahan ajar dengan baik untuk menarik minat belajar siswa. Penelitian ini bertujuan untuk mengembangkan LKS IPA terpadu menggunakan langkah-langkah metode kooperatif tipe STAD. Penelitian dijalankan menggunakan pendekatan kualitatif (Multi-case single-site case study design). Data dikumpulkan melalui dokumen analisis, dan dianalisis secara tematik berbantukan software NVIVO 10. Hasil penelitian menunjukkan bahwa langkah-langkah mengembangkan LKS IPA terpadu menggunakan metode kooperatif tipe STAD adalah: (i) Dalam LKS mesti ada pemberian motivasi dan apersepsi, (ii) pembentukan tim, (iii) presentasi dari guru, (iv) kegiatan belajar dalam tim mesti heterogen, (v) pelaksanaan kuis individu, (vi) pemberian penghargaan.
\end{abstract}

Kata kunci: Lembar Kerja Siswa, IPA Terpadu, Kooperatif Tipe STAD

\section{A. Pengenalan}

Ilmu Pengetahuan Alam (IPA) bukan hanya menekankan penguasaan pengetahuan berupa fakta, konsep, atau prinsip-prinsip saja, tetapi juga merupakan suatu proses penemuan secara saintifik, pembelajaran IPA berkaitan dengan cara mencari tahu tentang alam secara sistematis (Kurikulum, 2006). Menurut (Trianto, 2011) hakikat IPA dibangun atas dasar produk ilmiah, proses ilmiah, dan sikap ilmiah. Untuk mensukseskan tujuan pembelajaran IPA tersebut diperlukan berbagai bahan ajar dan sarana pendukung, salah satunya adalah pengunaan Lembar Kerja Siswa (LKS). LKS merupakan bahan ajar cetak yang disiapkan dan digunakan oleh guru untuk membantu siswa memperoleh pengetahuan, keterampilan dan nilai. Pembelajaran IPA menggunakan LKS dapat melibatkan siswa dan proses pembelajaran menjadi aktif dan efisien (Lee, 2014; Sasmaz-Oren, 2012). Beberapa penelitian mendapati bahwa di beberapa negara LKS menjadi kekuatan pendorong kurikulum (Martin, 2012). Bagaimanapun IPA terpadu yang dimaksud dalam penelitian ini adalah keterpaduan antara materi dengan istilah-istilah sains yang terdapat dalam Al-Qur'an. Penyampaian IPA secara terpadu diperlukan sarana berupa metode pembelajaran beserta perangkat pembelajaran yang sesuai (Rahayu.P, 2012). Menurut (Rimma A. Kutbiddinova, 2016) dengan metode akan terjalin interaksi antara guru dan siswa, dalam metode pembelajaran kooperatif misalnya akan terjadi kelompok diskusi, debat, game simulasi, bisnis, analisis situasi kasus, metode proyek, pelatihan sosial-psikologis, moderasi, dan simulasi komputer.

Kooperatif tipe STAD diasumsikan dapat meningkatkan prestasi belajar siswa, hubungan sosial, menumbuhkan sikap menerima kelebihan dan kekurangan diri-sendiri dan orang lain, serta meningkatkan harga diri siswa (R. E. Slavin, 2011). Pemilihan metode ini didasarkan pada beberapa hasil penelitian tentang penggunaan kooperatif tipe STAD yang banyak dikaitkan dengan prestasi akademik, sikap sosial, interaksi dan hubungan interpersonal (Bernaus, 2008). Selain itu, dalam kooperatif tipe STAD siswa merasa lebih dihargai saat mengeluarkan gagasan dalam pikiran mereka, karena keberhasilan tim dalam tipe STAD bergantung keberhasilan individu dari semua anggota tim tersebut (Jacobs, 2006).

Lembar Kerja Siswa merupakan lembaran-lembaran berisi tugas yang harus dikerjakan oleh siswa (Majid, 2008). Keterlibatan siswa dalam mengembangkan dan menggunakan LKS membantu mereka dalam proses belajar (Gunes, 2005; Tutak, 2008a, 2008b), serta memastikan siswa agar belajar dalam lingkungan 
pembelajaran (Bak-Kibar, 2010a, 2010b). Justeru, penggunaan LKS dalam pembelajaran membuat siswa lebih mudah memahami permasalahan dalam memahami satu topik pembelajaran (Bozdogan, 2007). LKS berbentuk teks berbasis cetak menuntut enam elemen, yaitu konsistensi, format, organisasi, daya tarik, ukuran huruf, dan penggunaan spasi kosong (Arsyad, 2013). Beberapa penelitian mendapati bahwa LKS yang menarik adalah LKS yang diperkaya dengan gambar kartun (Burhan, 2008; Karamustafaoglu, 2005), gambar konseptual, dan pertanyaan evaluasi (Karamustafaoglu, 2005), karena pertanyaan evaluasi merupakan faktor penting dalam LKS (Calderhead, 2006).

Fakta di sekolah menunjukkan bahwa LKS IPA terpadu masih sangat minim elemen-elemen yang dipaparkan tersebut, sehingga siswa kurang tertarik menggunakan LKS dalam proses pembelajaran. Faktanya adalah guru memberikan selembaran LKS kepada siswa hanya saat melakukan kegiatan, dan LKS yang digunakan tidak memenuhi elemen yang dipaparkan sebelum ini. Penelitian (Kisiel, 2003b) menemukan bahwa siswa tidak akan belajar jika mereka tidak memiliki LKS. Fry (1987) dalam penelitiannya bahwa guru menyetujui LKS digunakan sebagai sarana belajar, dapat mengatasi kesulitan belajar, dan meningkatkan pengalaman belajar. Beberapa pakar menemukan siswa merasa kesulitan memahami materi fisika secara mandiri, metode pengajaran yang buruk, siswa kurang terampil, dan banyak lainnya (Ajaja, 2002; Jegede, 2007; Yusuf, 2010). Selain itu dalam tim belajar, tidak semua tim bekerja sama secara kooperatif (Van Wyk, 2010). Juteru, dalam proses pembelajaran guru harus pandai memilih metode, teknik dan bahan pengajaran yang tepat, agar hasil belajar siswa sesuai dengan tujuan yang diharapkan (Sugiharto, 2015).

Pengembangan LKS menggunakan metode kooperatif tipe STAD diamsumsikan dapat membantu mensolusikan permasalahan pembelajaran. Proses pembelajaran menggunakan pendekatan ini dapat membantu siswa dalam anggota kelompok agar bekerja sama dengan lebih efektif (Amornsinlaphachai, 2012; Anowar Hossain, 2013; Kasiková, 2007; Macarena Navarro-Pablo, 2015). Metode ini juga dapat membantu meningkatkan pemahaman siswa, karena mereka bekerja dalam mencapai tujuan bersama, seperti keterampilan sosial untuk mencapai dan menguasai konsep serta bahan ajar yang dirancang oleh guru (Sugiharto, 2015). Selain itu, penyelesaian masalah pada materi fisika lebih mudah dikerjakan dalam tim belajar daripada individu (Jonassen, 2001). Para pakar melaporkan bahwa kooperatif tipe STAD lebih efektif daripada strategi pembelajaran individu, metode diskusi, dan instruksi kelas konvensional (Keramati, 2010; Taiwo, 2008), karena pembelajaran kooperatif dapat membantu siswa untuk mengembangkan keterampilan dalam komunikasi lisan, dan keterampilan sosial mereka (Monchai Tiantong \& Sanit Teemuangsai, 2013). Sehingga, minat belajar kooperatif terus meningkat di tahun-tahun berikutnya (Elif Akdemir, 2012).

\section{B. Metodologi}

Penelitian ini dijalankan menggunakan pendekatan kualitatif (Multi-case single-site case study design). Data dikumpulkan melalui dokumen analisis (Darlington, 2002). Dokumen digunakan sebagai sumber data dan dimanfaatkan sebagai pembuktian, menafsirkan, dan memaknai suatu peristiwa (Moleong, 2007). Lebih lanjut (Moleong, 2007) memberikan alasan mengapa analisis dokumen penting dalam penelitian kualitatif; (i) merupakan sumber yang stabil, kaya dan mendorong, (ii) sebagai bukti (evident) dalam pengujian, (iii) sifatnya alamiah, sesuai konteks, lahir, dan berada dalam konteks, (iv) murah dan tidak sukar ditemukan, hanya membutuhkan waktu, (v) membuka kesempatan untuk memperluas pengetahuan terhadap permasalahan yang diteliti. Semua data yang diperoleh melalui dokumen tersebut dianalisis secara tematik berbantukan software NVIVO 10.

\section{Hasil Penelitian dan Pembahasan}

Hasil penelitian menunjukkan bahwa langkah-langkah pengembangan LKS IPA terpadu menggunakan metode kooperatif tipe STAD berdasarkan analisis dokumen (Isiaka Amosa Gambari, 2015; Mohamad Nur, 2005; R. Slavin, K \& Oickle, 1981; R. E. Slavin, 1978, 1983, 1988; R. E. Slavin, 1990; R. E. Slavin, 1991; R. E. Slavin, 1995, 2005, 2008; Sugiyanto, 2007; Monchai Tiantong1 \& Sanit Teemuangsai, 2013) adalah dalam LKS mesti ada; Pertama, pemberian motivasi dan apersepsi; Guru menyampaikan tujuan belajar serta memberikan motivasi kepada siswa dalam mencapai kompetensi dan tujuan pembelajaran. Penentuan motivasi dan apersepsi dalam LKS IPA terpadu, peneliti melihat silabus sebagai pedoman penulisan. Kedua, pembentukan tim; hal ini sangat penting dalam kooperatif tipe STAD. Pembentukan tim dibagi secara 
heterogen, berikut berdasarkan analisis dokumen (R. E. Slavin, 1988). Ketiga, presentasi dari guru; dalam hal ini peneliti menganalisis silabus dan melihat indikator yang akan dicapai oleh siswa. Keempat, kegiatan belajar dalam tim mesti heterogen. Kelima, pelaksanaan kuis individu; peneliti menganalisis berdasarkan silabus dan indikator pencapaian pembelajaran. Kenam, pemberian penghargaan; Langkah-langkah memberi penghargaan pada kelompok adalah sebagai berikut. (a) Menentukan nilai dasar (awal) masing-masing siswa; (b) Menentukan nilai tes atau kuis yang telah dilaksanakan setelah siswa bekerja dalam kelompok, misalnya nilai kuis 1 , nilai kuis 2 atau nilai rata-rata kuis 1, nilai rata-rata kuis 2. (c) Menentukan nilai peningkatan hasil belajar yang ditentukan berdasarkan selisih nilai kuis dan nilai dasar masing-masing siswa dengan menggunakan konversi perolehan siswa terhadap konstribusi dalam kelompoknya.

Bahan ajar dan LKS yang ideal adalah perangkat yang dapat memberikan informasi dan pengalaman belajar, dikembangkan dengan karakteristik dan desain yang baik (Tomlinson, 2012). Beliau juga memaparkan bahwa LKS merupakan perangkat yang informatif (menginformasikan tujuan pembelajaran), terdapat metode pembelajaran (tatap muka belajar dan praktek), merumuskan pengalaman, motivasi dan eksplorasi. Bagaimanapun pandangan ini sejalan dengan hasil penelitian bahwa pengembangan LKS IPA terpadu memiliki karakteristik yang berbeda dan didesain sesuai dengan pedoman penulisan LKS yang baik. Karakteristik pengembangan LKS IPA terpadu adalah di dalam LKS termuat secara tertulis langkah-langkah metode kooperatif tipe STAD. Peneliti setuju dengan pandangan (Tomlinson, 2012) bahwa langkah pertama pengembangan LKS IPA terpadu ini yaitu pemberian motivasi dan apersepsi.

Hasil penelitian (Fajola, 2000) dan (Ghaith, 2003) menemukan bahwa kognitif, afektif dan psikomotorik prestasi keterampilan siswa laki-laki lebih baik daripada siswa perempuan. Temuan tersebut menggambarkan bahwa terdapat hubungan antara gender, suku atau ras dan prestasi akademik dalam pembelajaran sains. Hasil pengembangan LKS IPA terpadu menggunakan metode kooperatif tipe STAD salah satu langkah-langkah kerja yaitu pembentukan tim belajar. Tim belajar dalam kooperatif tipe STAD adalah bersifat heterogen, yaitu berdasarkan jenis kelamin, tingkat prestasi, suku atau ras, dan karakteristik siswa lainnya (R. E. Slavin, 2011). Setiap tim terdiri atas 4 atau 5 orang, kemudian mengambil kuis individu, dan menghitung kemajuan tim yaitu untuk melihat sejauh mana tingkat pemahaman siswa

Selanjutnya langkah pengembangan LKS IPA terpadu kooperatif tipe STAD adalah kegiatan belajar dalam tim belajar (kelompok heterogen). Pembentukan tim dilakukan oleh guru, dan siswa tidak boleh membentuk tim belajar sendiri (R. E. Slavin, 1988). Beliau juga mengungkapkan bahwa pembentukan tim harus seimbang (R. E. Slavin, 1988). Yu dalam penelitiannya menemukan bahwa subjek dalam tim kooperatif tipe STAD memiliki skor yang lebih tinggi pada posttest dan kuesioner (Yu, 1998). Diperkuat oleh Noornia, bahwa tim belajar kooperatif tipe STAD membawa pengaruh positif terhadap kegiatan belajar siswa, memberikan kemajuan comphension siswa, memberikan pengetahuan khusus terhadap tim siswa cerdas dan tim siswa kurang cerdas, mendorong setiap tim memiliki rasa prihatin pada tim lain (Noornia, 1997). Selain itu, dalam STAD siswa tidak hanya mengerjakan tugas dalam tim, tetapi untuk belajar sebagai tim (M. Nur, 2008). Jadi, peneliti menyimpulkan bahwa dengan mengembangkan LKS IPA terpadu menggunakan metode kooperatif tipe STAD, siswa akan sangat terbantu. Setiap siswa sebagai anggota tim dapat belajar menempatkan diri, bekerja sama, bersosialisasi, saling menghargai gagasan antar tim, dan dapat belajar menerapkan nilai-nilai sikap kooperatif tipe STAD dalam suatu tim untuk mencapai tujuan belajar.

Beberapa peneliti menganjurkan untuk menggunakan kooperatif tipe STAD sebagai metode utama yang digunakan di dalam kelas (Johnson, 1975; Sharan, 1979; R. E. Slavin). (Featherstone, 1986) dalam penelitiannya mendapati bahwa belajar kooperatif dapat membantu siswa karena dalam tim semua siswa dapat meningkatkan pemahaman mereka dengan cara menjelaskan ide mereka kepada orang lain. Selain itu, tugas siswa dalam tim kooperatif tidak hanya untuk mengisi LKS tetapi harus memahami konsep-konsep materi pelajaran (R. Slavin, K, 2010; R. E. Slavin, 2011). Beliau juga menemukan bahwa siswa dalam pembelajaran kooperatif lebih mampu bersosialisasi bukannya terisolasi, menyenangkan bukan membosankan (R. E. Slavin, 2011). Hasil temuan tersebut membolehkan peneliti menggunakan metode kooperatif, sehingga memungkinkan pembelajaran tidak membosankan dan siswa dapat meningkatkan rasa sosialisasi antar tim belajar. 


\section{Kesimpulan}

Satu keterampilan yang harus dimiliki seorang guru adalah memberikan bahan ajar yang menarik kepada siswa, karena bahan ajar merupakan ruh utama dalam proses pembelajaran. Perkembangan pendidikan menjadikan keterampilan dan kognitif siswa berbeda-beda, sehingga guru harus dapat memberi satu-kesatuan bahan ajar yang mampu mengkoordinasi hal tersebut. Dengan demikian, proses pembelajaran menjadi lebih bermakna dan diminati oleh siswa.

\section{E. Rujukan}

Ajaja, O. P. (2002). Assessment of biology study support environments in schools. In STAN 41st Annual Conference Proceedings, 215-218.

Amornsinlaphachai, P. a. D., K. (2012). Developing the Model of Web-Based Learning Environment Enhancing Problem-Solving for Higher Education Students. American Journal of Scientific Research, 52, 21-32.

Anowar Hossain, R. A. T. (2013). Effects of cooperative learning on students' achievement and attitudes in secondary mathematics. Procedia - Social and Behavioral Sciences, 93(2013), 473 - 477.

Arsyad, A. (2013). Media Pembelajaran. Jakarta: Raja Grafindo Remaja.

Bak-Kibar, Z. v. A., A. (2010a). Developing a worksheet about physical and chemical event. Procedia Social and Behavioral Sciences, 2, 739-743.

Bak-Kibar, Z. v. A., A. (2010b). Implementing of a workshe- et related to physical and chemical change concepts. Procedia Social and Behavioral Sciences, 2, 733-738.

Bernaus, M. G., R.C. (2008). Teacher motivation strategies, student perceptions, student motivation, and English achievement. The Modern Language Journal, 92, 387-401.

Bozdogan, A. (2007). Fen bilgisi ogretiminde calssma yaprak-ları ile ogretimin ogrencilerin fen bilgisi tutumuna ve mantiksal dusunme becerilerine etkisi. Yayimlanmamis yuksek lisans tezi, Cukurova Universitesi, Sosyal Bilimler Enstitusu, Adana.

Burhan, Y. (2008). Developing worksheets enriched by concept cartoons concerning the acid-base concepts. Karadeniz Technical University Graduate School of Natural and Applied Sciences.

Calderhead, W. J., Filter, K. J., \& Albin, R. W. (2006). An investigation of incremental effects of interspersing math items on task-related behavior. Journal of Behavioral Education, 15(1), 51-65.

Darlington, Y. S., Dorothy. (2002). Qualitative Research in Practise: Stories From the Field. Crows Nest: Allen \& Unwin.

Elif Akdemir, A. A. (2012). From Past to Present: Trend Analysis of Cooperative Learning Studies. Procedia Social and Behavioral Sciences, 55(2012), $212-217$.

Fajola, O. O. (2000). Effect of three modes of computer Based instructional strategies on students learning outcomes in biology. University of Ibadan, Ibadan, Nigeria. Retrieved from Unpublished Ph.D thesis

Featherstone, H. (1986). Cooperative learning. Harvard Education Letter, 4-6.

Ghaith, G. (2003). Effects of the learning together model of cooperative learning on English as a Foreign Language reading achievement, academic self-esteem, and feelings of school alienation, American University of Beirut. Bilingual Research Journal, 27(3).

Gunes, G. v. A., A. (2005). Olusturmacı yaklasıma gore ta- sarlanan ogrenme ortamının matematik basarısına etkisi. Gazi Universitesi, Gazi Egitim Fakultesi Dergisi, 25 (1), 105-121.

Isiaka Amosa Gambari, M. O. Y., David Akpa Thomas. (2015). Effects of Computer-Assisted STAD, LTM and ICI Cooperative Learning Strategies on Nigerian Secondary School Students' Achievement, Gender and Motivation in Physics. Akpa Malaysian Online Journal of Educational Sciences, 3, 11-26.

Jacobs, G. (2006). Cooperative Learning and Second Language Teaching. Cambridge University Press.

Jegede, S. A. (2007). Student's anxiety towards the learning of Chemistry in some Nigerian secondary schools. Educational Research and Review, 2(7), 193-197.

Johnson, D. W., \& Johnson, R. T. (1975). Learning together and alone. Englewood Cliffs, New Jersey: Prentice-Hall, Inc.

Jonassen, D. K., H. (2001). Communication patterns in computer-mediated versus face-to-face group problem solving. Educational Technology Research \& Devt, 49(11), 35 - 51.

Karamustafaoglu, O., Yaman, S. ve Karamustafaoglu, S. (2005). Fen ve teknoloji egitiminde ogrenme ve ogretim materyalleri. M. Aydogdu ve T. Kesercioglu (Ed.), Illkogretimde fen ve tekno-loji ogretimi icinde 212-234. 
Kasíková, H. (2007). Kooperativní učení a vyučování. Teoretické a praktické problémy. Univerzita Karlova v Praze : Karolinum.

Keramati, M. (2010). Effect of cooperative learning on academic achievement of physics course. Journal of Computers in Mathematics and Science Teaching, 29(2), 155 -173.

Kisiel, J. (2003b). Teachers, museums and worksheets: A closer look at a learning experience. Journal of Science Teacher Education, 14(1), 3-21.

Kurikulum, P. (2006). Pembelajaran Tematik. Jakarta: Departemen Pendidikan Nasional

Lee, C. D. (2014). Worksheet usage, reading achievement, classes' lack of readiness and science achievement: A cross-country comparison. International Journal of Education in Mathematics, Science and Technology, 2(2), 96-106.

Macarena Navarro-Pablo, E. J. G.-S. (2015). Teaching to training teachers through cooperative learning. Procedia - Social and Behavioral Sciences, 180(2015), 401 - 406.

Majid, A. (2008). Perencanaan Pembelajaran Mengembangkan Standar Kompetensi Guru . Bandung: PT. Rosdakarya.

Martin, M. O., Mullis, I. V. S., Foy, P, \& Stanco, G. M. (2012). TIMSS2011 international results in science. Chestnut Hill, M.A: TIMSS \& PIRLS International Study Center.

Moleong, L. J. (2007). Metodologi Penelitian Kualitatif. Bandung: PT Remaja Rosdakarya Offset.

Noornia, A. (1997). Implementation of Cooperative Learning with STAD Method in Teaching Percent in Class IV SDI Maarif 02 Pematang Singosari. Malang.

Nur, M. (2005). Pembelajaran Kooperatif. Surabaya: Pusat Sains dan Matematika Sekolah UNESA.

Nur, M. (2008). Cooperative Learning. UNESA, Surabaya

Rahayu.P, S. M., dan Miswadi. (2012). Pengembangan Pembelajaran Ipa Terpadu Dengan Menggunakan Model Pembelajaran Problem Base Melalui Lesson Study. Program Pascasarjana.

Rimma A. Kutbiddinova, A. A. E., Marina A. Romanova. (2016). The Use of Interactive Methods in the Educational Process of the Higher Education Institution. International Journal Of Environmental \& Science Education, 11(14), 6557-6572.

Sasmaz-Oren, F. O., U. . (2012). An application about pre-service teachers' development and use of worksheets and an evaluation of their opinions about the application. Educational Sciences: Theory and Practice, 12(1), 263-270.

Sharan, S. (1979). Cooperative learning in teams:A Critical review of 'recent methods and effects on achievement,attitudes, and racelethnicrelations: Unpublished manuscript.

Slavin, R., K. (2010). Cooperative Learning. Universitas Johns Hopkins: Baltimore, MD, AS.

Slavin, R., K \& Oickle. (1981). Effectsof Cooperative Learning Teams on Studen tAchievement and Race Relations:Treatmentby Race Interactions. Sociology of Educa-tion, 54, 174-180.

Slavin, R. E. Cooverative Learning.Review of Educational Research,vs. in press.(a).

Slavin, R. E. (1978). StudentTeamsand Achievement Divisions. Journal of Researchand Development in Education, 12, 39-49.

Slavin, R. E. (1983). Student Team Learning: An Overview and Practical Guide. Washing-ton, D.C: National Education Association.

Slavin, R. E. (1988). Student team learning: An overview and practical guide (2 ed.). Washington D.C: National Education Association.

Slavin, R. E. (1990). Cooperative learning: Theory, research, and practice. Englewood Cliffs, NJ: Prentice Hall.

Slavin, R. E. (1991). Student team learning: A practical guide to cooperative learning (3 ed.).

Slavin, R. E. (1995). Cooperative Learning : Theory, Research and Practice. Massachusetts: Allyn and Publishers.

Slavin, R. E. (2005). Cooperative learning: Theory, research, and practice. Englewood Cliffs, NJ: Prentice Hall.

Slavin, R. E. (2008). Cooperative learning: Theory, research, and practice. Englewood Cliffs, NJ: Prentice Hall.

Slavin, R. E. (2011). Instruction Based on Cooperative Learning. In R. E. Mayer, \& P. A. Alexander (Eds.), Handbook of Research on Learning and Instruction. New York: Taylor \& Francis.

Sugiharto. (2015). The Effect of Cooperative Learning Model and Kolb Learning Styles on Learning Result of The Basics of Politics. Journal of Education and Practice, 6(21). 
Sugiyanto. (2007). Modul Guruan dan Latihan Profesi Guru (PLPG), Model-model Pembelajaran Inovatif. Panitia Sertifikasi Guru Rayon 13 Surakarta.

Taiwo, O. A. (2008). Relative effectiveness of ICI and CCI packages on the performance of students in senior secondary school mathematics in Minna. Unpublished B.Tech. Project, Department Science Education, Federal University of Technology, Minna .

Teemuangsai, M. T. S. (2013). Student Team Achievement Divisions (STAD) Technique through the Moodle to Enhance Learning Achievement. International Education Studies by Canadian Center of Science and Education, 6(4).

Teemuangsai, M. T. S. (2013). Student Team Achievement Divisions (STAD) Technique through the Moodle to Enhance Learning Achievement. International Education Studies, 6.

Tomlinson, B. (2012). Material Development for Language Learning and Teaching. Cambridge Journal Lang Teach, 45(2), 143-179.

Trianto. (2011). Model Pembelajaran Terpadu Konsep,Strategi Dan Implementasinya Dalam Kurikulum Tingkat Satuan Pendidikan (KTSP). Jakarta: Bumi Aksara.

Tutak, T. v. B., O. (2008a). Dinamik geometri yazllımı ile geometri ogretiminin ogrencilerin van heile geometri anlama du-zeylerine etkisi. 8th International Educational Technology Con-ference, Eskisehir(1058-1061).

Tutak, T. v. B., O. (2008b). Geometri ogretiminde bilgisa-yar destekli ogretimin ogrenci basarısma etkisi. 8 th International Educational Technology Conference (s. 1062-1065), Eskisehir.

Van Wyk, M. M. (2010). Do student teams achievement divisions enhance economic literacy? A quasiexperimental design. Journal of Social Science, 23(2), 83-89.

Yu, F. Y. (1998). The Effects of Cooperation With Inter-Group Competition on Performance and Attitudes in a Computer-Assisted Science Instruction. Journal of Computers in Mathematics and Science Teaching, Charlottesville, VA: AACE., 17(4), 381-395.

Yusuf, M. O., \& Afolabi, A. O. (2010). Effects of Computer Assisted Instruction (CAI) on Secondary School Students' Performance in Biology. The Turkish Online Journal of Educational Technology, 9(1). 